
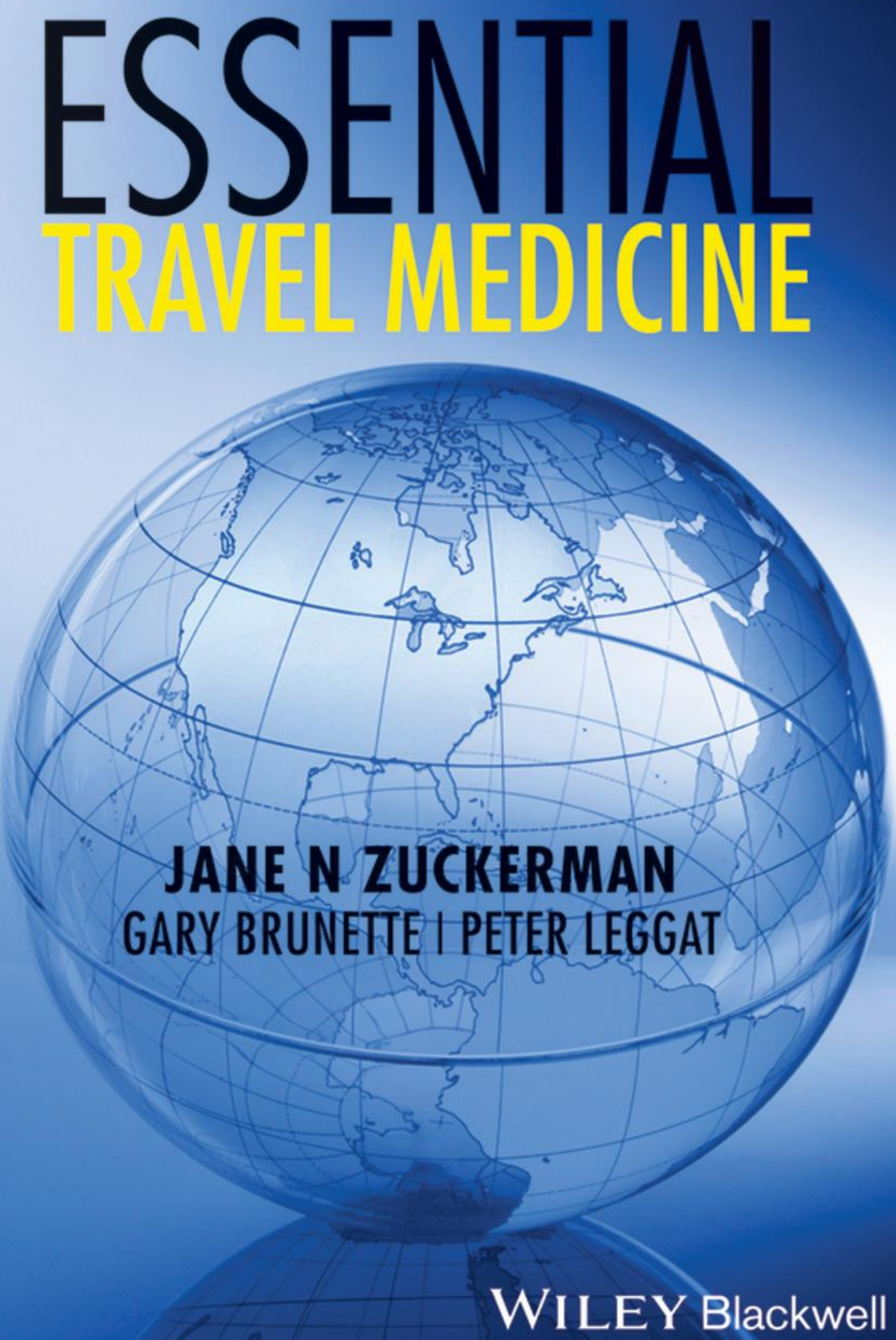
Essential Travel Medicine 


\section{Essential Travel Medicine}

EDITED BY

\section{Jane N. Zuckerman, MD, FRCP, FRCPath, FFPH, FFPM, FFTM}

Consultant in Travel Medicine

Honorary Senior Lecturer, UCL Medical School, University College London, UK;

Honorary Consultant, Royal Free London NHS Foundation Trust and Great Ormond Street Hospital for Children NHS Foundation Trust, London, UK;

Adjunct Professor, College of Public Health, Medical and Veterinary Sciences, James Cook University, Townsville, Qld, Australia

\section{Gary W. Brunette, MD, MS, FFTM}

Chief, Travelers' Health Branch

Division of Global Migration and Quarantine

Centers for Disease Control and Prevention, Atlanta, GA, USA

\section{Peter A. Leggat, AM, MD, PhD, DrPH, FAFPHM, FFPH, FFPM(Hon), FACTM(Hon), FFTM, FACAsM}

Professor and Dean, College of Public Health, Medical and Veterinary Sciences, James Cook University, Townsville, Qld, Australia;

Visiting Professor, School of Public Health, Faculty of Health Sciences, University of the Witwatersrand, Johannesburg, South Africa;

Conjoint Professor, School of Health Sciences, Faculty of Health, University of Newcastle, NSW, Australia; Adjunct Professor, Research School of Population Health, College of Medicine, Biology and Environment, Australian National University, Canberra, ACT, Australia

\section{WI LEY Blackwell}


This edition first published 2015 @ 2015 by John Wiley \& Sons, Ltd

Registered office: John Wiley \& Sons, Ltd, The Atrium, Southern Gate, Chichester, West Sussex, PO19 8SQ, UK

Editorial offices: 9600 Garsington Road, Oxford, OX4 2DQ, UK

The Atrium, Southern Gate, Chichester, West Sussex, PO19 8SQ, UK

111 River Street, Hoboken, NJ 07030-5774, USA

For details of our global editorial offices, for customer services and for information about how to apply for permission to reuse the copyright material in this book please see our website at www.wiley.com/wiley-blackwell

The right of the author to be identified as the author of this work has been asserted in accordance with the UK Copyright, Designs and Patents Act 1988.

All rights reserved. No part of this publication may be reproduced, stored in a retrieval system, or transmitted, in any form or by any means, electronic, mechanical, photocopying, recording or otherwise, except as permitted by the UK Copyright, Designs and Patents Act 1988, without the prior permission of the publisher.

Designations used by companies to distinguish their products are often claimed as trademarks. All brand names and product names used in this book are trade names, service marks, trademarks or registered trademarks of their respective owners. The publisher is not associated with any product or vendor mentioned in this book. It is sold on the understanding that the publisher is not engaged in rendering professional services. If professional advice or other expert assistance is required, the services of a competent professional should be sought.

The contents of this work are intended to further general scientific research, understanding, and discussion only and are not intended and should not be relied upon as recommending or promoting a specific method, diagnosis, or treatment by health science practitioners for any particular patient. The publisher and the author make no representations or warranties with respect to the accuracy or completeness of the contents of this work and specifically disclaim all warranties, including without limitation any implied warranties of fitness for a particular purpose. In view of ongoing research, equipment modifications, changes in governmental regulations, and the constant flow of information relating to the use of medicines, equipment, and devices, the reader is urged to review and evaluate the information provided in the package insert or instructions for each medicine, equipment, or device for, among other things, any changes in the instructions or indication of usage and for added warnings and precautions. Readers should consult with a specialist where appropriate. The fact that an organization or Website is referred to in this work as a citation and/or a potential source of further information does not mean that the author or the publisher endorses the information the organization or Website may provide or recommendations it may make. Further, readers should be aware that Internet Websites listed in this work may have changed or disappeared between when this work was written and when it is read. No warranty may be created or extended by any promotional statements for this work. Neither the publisher nor the author shall be liable for any damages arising herefrom.

Library of Congress Cataloging-in-Publication Data applied for.

A catalogue record for this book is available from the British Library.

ISBN: 9781118597255

Wiley also publishes its books in a variety of electronic formats. Some content that appears in print may not be available in electronic books.

Cover image: Globe-North America @DNY59 (iStockphoto.com)

Set in 9/12pt, MeridienLTStd by SPi Global, Chennai, India 


\section{Contents}

List of contributors, vii

Preface, xv

Acknowledgments, xvii

\section{Section 1: Travel medicine}

1 Basic epidemiology of infectious diseases, 3 Mark J. Sotir $\theta$ David O. Freedman

2 Basic epidemiology of non-infectious diseases, 9 Richard C. Franklin \& Peter A. Leggat

3 Pre-travel health risk assessment, 23 Peter A. Leggat $\theta$ Jane N. Zuckerman

4 Setting up a travel clinic, 35 Marc T.M. Shaw $\theta$ Claire S. Wong

5 Travel medicine resources, 45 Peter A. Leggat, Gary W. Brunette, Gilles Poumerol, \& Jane N. Zuckerman

\section{Section 2: Travel-related infectious diseases}

6 Travelers' diarrhea, 57 Charles D. Ericsson

7 Vector-borne diseases, 65 Annelies Wilder-Smith

8 Yellow fever, 75 Mark D. Gershman $\theta$ J. Erin Staples

9 Malaria, 83 Tomas Jelinek

10 Respiratory disease, 95 Regina LaRocque $\theta$ Edward T. Ryan

11 Sexually transmitted infections, 103 Alberto Matteelli, Anna Cristina C. Carvalho, e Patricia Schlagenhauf

12 Tropical skin infections, 115 Francisco Vega-López et Sara Ritchie

13 Rabies, 121 Mary J. Warrell

14 Vaccine-preventable diseases, 131 Joseph Torresi, Abinash Virk $\theta$ Jane N. Zuckerman 


\section{Section 3: Travelers with underlying medical problems and special needs}

15 Women's health and travel, 167

I. Dale Carroll

16 Traveling with children, 173

Karl Neumann, Andrea P. Summer, o Philip R. Fischer

17 Travelers with underlying medical conditions, 187

Anne E. McCarthy o Kathryn N. Suh

18 The older traveler and traveling with disability, 199

Kathryn N. Suh $\theta$ Anne E. McCarthy

19 Visiting friends and relatives, 209

Karin Leder $\theta$ Sarah L. McGuinness

20 Migrants, refugees, and travel medicine, 215

Louis Loutan

21 Study-abroad programs: student health and safety issues, 221

Gary Rhodes e Gary W. Brunette

22 Humanitarian aid workers, disaster relief workers, and missionaries, 227

Brian D. Gushulak $\theta$ Douglas W. MacPherson

23 Long-term travelers, 235

Claire Davies $\theta$ Ted Lankester

\section{Section 4: Environmental travel health risks}

24 Aviation and travel medicine, 243

Michael Bagshaw, Ian C. Cheng $\theta$ Robert Bor

25 Expedition and wilderness medicine, 257

Sean T. Hudson, Will Smith, David R. Shlim, Caroline J. Knox $\theta$ Karen J. Marienau

26 Venomous poisonous animals and toxins, 279

Mark A. Read

27 Cruise ships and travel medicine, 285

Sally S.J. Bell $\theta$ Eilif Dahl

28 Mass gatherings and travel medicine, 293

Joanna Gaines e Gary W. Brunette

29 Emergency care whilst abroad, 301

Peter A. Leggat $\theta$ Marc T.M. Shaw

\section{Section 5: Post-travel medicine}

30 The returning traveler, 313

Tamar Lachish, Alfons Van Gompel e Eli Schwartz 


\section{List of contributors}

Michael Bagshaw, MB, BCh, MRCS, FFOM, DAvMed, DFFP, FRAeS

Visiting Professor of Aviation Medicine

Honorary Civilian Consultant Adviser in Aviation Medicine to the Army

King's College London

London, UK;

Cranfield University

Cranfield, UK

Sally S.J. Bell, MB BS, Master in Maritime Medicine

Clinical Quality Consultant

London, UK

\section{Robert Bor, DPhil, CPsychol, CSci, FBPsS, UKCP, Reg FRAeS}

Professor, Lead Consultant Clinical, Counselling and Health Psychologist Royal Free London NHS Foundation Trust;

Director, Dynamic Change Consultants

London, UK

Gary W. Brunette, MD, MS, FFTM

Chief, Travelers' Health Branch

Division of Global Migration and Quarantine

Centers for Disease Control and Prevention

Atlanta, GA, USA

I. Dale Carroll, MD, FACOG, DTM\&H, FFTM RCPS (Glasgow)

Medical Director

The Pregnant Traveler

Spring Lake, MI, USA

Ian C. Cheng, BE, BMed, DipOccEnvironHealth, DipAvMed, MPH, FAFOEM, FACAsM

Adjunct Associate Professor

College of Public Health, Medical and Veterinary Sciences

James Cook University

Townsville, Queensland, Australia;

Staff Specialist - Occupational Medicine

Royal North Shore Hospital

Sydney, NSW, Australia 


\section{Anna Cristina C. Carvalho, MD, PhD}

Researcher in Public Health

Laboratory of Innovations in Therapies, Education and Bioproducts)

Oswaldo Cruz Institute, FioCruz

Rio de Janeiro, Brazil

\section{Eilif Dahl, MD, MHA, PhD}

Professor Emeritus, University of Bergen

Norwegian Centre for Maritime Medicine

Haukeland University Hospital

5021 Bergen

Norway

\section{Claire Davies, MRCP, MRCGO, DTM\&H, MFTM RCPS (Glasgow)}

Medical Team Manager/Travel Health Clinician

InterHealth Worldwide

London, UK

\section{Charles D. Ericsson, MD}

Professor of Medicine and Dr. and Mrs. Carl V. Vartian Professor of Infectious Diseases;

Head, Clinical Infectious Diseases

University of Texas Medical School at Houston

Houston, TX, USA

\section{Philip R. Fischer, MD, DTM\&H}

Professor of Pediatrics

Mayo Clinic

Rochester, MN, USA

\section{Richard C. Franklin, BSc, MSocSc, PhD}

Associate Professor, College of Public Health, Medical and Veterinary Sciences

James Cook University

Townsville, Queensland, Australia;

Royal Life Saving Society, Australia

\section{David O. Freedman, MD}

Professor of Medicine and Epidemiology

Division of Infectious Diseases

University of Alabama at Birmingham

Birmingham, AL, USA

\section{Joanna Gaines, PhD, MPH}

Doctoral Epidemiologist

Travelers' Health Branch

Division of Global Migration and Quarantine

Centers for Disease Control and Prevention

Atlanta, GA, USA 
Mark D. Gershman, MD

Medical Epidemiologist

Travelers' Health Branch

Division of Global Migration and Quarantine

Centers for Disease Control and Prevention

Atlanta, GA, USA

Brian D. Gushulak, BSc (Hon), MD

Medical Consultant

Migration Health Consultants, Inc.

P.O. Box 463

Qualicum Beach, BC, Canada

\section{Sean T. Hudson, MBBS, MSc, FAWM, Dip Mtn Med}

General Practitioner and Honorary Consultant

Accident and Emergency

Maryport Health Centre

West Cumberland Hospital

Maryport, Cumbria, UK;

Director and Founder, Expedition Medicine

Cumbria, UK

Tomas Jelinek, MD

Medical Director

Berlin Center for Travel and Tropical Medicine

Berlin, Germany

\section{Caroline J. Knox, MBBS MSc MRCGP}

General Practitioner, Castlegate Surgery

Cockermouth, Cumbria, UK;

Founder, Expedition Medicine

Cumbria, UK

Tamar Lachish, MD

Senior Doctor, Infectious Diseases Unit and the Internal Medicine Ward

Shaare-Zedek Medical Center

Jerusalem, Israel

Ted Lankester, MA, MB, Bchir, MRCGP, FFTM, RSPSG

Director of Health Services

InterHealth Worldwide

London, UK

\section{Regina LaRocque, MD, MPH}

Co-Director, Global TravEpiNet (GTEN) Program

Massachusetts General Hospital;

Assistant Professor of Medicine, Harvard Medical School

Boston, MA, USA 


\section{Karin Leder, MBBS, FRACP, PhD, MPH, DTMH}

Associate Professor, Head of Infectious Disease Epidemiology Unit

Department of Epidemiology and Preventive Medicine

School of Public Health and Preventive Medicine

Monash University

Melbourne, VIC, Australia;

Head of Travel Medicine and Immigrant Health

Royal Melbourne Hospital at the Doherty Institute for Infection and Immunity

Melbourne, VIC, Australia;

Victorian Infectious Diseases Service

Royal Melbourne Hospital

Parkville, VIC, Australia

Peter A. Leggat, AM. MD, PhD, DrPH, FAFPHM, FFPH, FFPM(Hon), FACTM(Hon),

\section{FFTM, FACAsM}

Professor and Dean, College of Public Health, Medical and Veterinary Sciences

James Cook University

Townsville, Queensland, Australia;

Visiting Professor, School of Public Health, Faculty of Health Sciences

University of the Witwatersrand

Johannesburg, South Africa;

Conjoint Professor, School of Health Sciences

Faculty of Health

University of Newcastle

Newcastle, New South Wales, Australia;

Adjunct Professor, Research School of Population Health

College of Medicine, Biology and Environment

Australian National University

Canberra, ACT, Australia

\section{Louis Loutan, MD, MPH}

Professor, Division of International and Humanitarian Medicine

Department of Community Medicine and Primary Care

University Hospital of Geneva

Geneva, Switzerland

\section{Douglas W. MacPherson, MD, MSc(CTM), FRCPC}

Migration Health Consultants, Inc.

Qualicum Beach, BC, Canada;

Associate Professor, Pathology and Molecular Medicine

McMaster University

Hamilton, ON, Canada 


\section{Karen J. Marienau, MD, MPH}

Medical Consultant and Advisor St. Paul, MN, USA;

Formerly Division of Global Migration and Quarantine US Centers for Disease Control and Prevention Atlanta, GA, USA

\section{Alberto Matteelli, MD}

Head of Community Infection Unit

Clinic of Infectious and Tropical Diseases

Spedali Civili Hospital

University of Brescia

Brescia, Italy

Anne E. McCarthy, MD, MSc, FRCPC, DTM\&H, FASTMH

Professor of Medicine, University of Ottawa;

Director, Tropical Medicine and International Health Clinic

University of Ottawa

Ottawa, Canada

\section{Sarah L. McGuinness, MBBS, BMedSc, DTMH}

Infectious Diseases Registrar

Victorian Infectious Diseases Service

Royal Melbourne Hospital

Parkville, VIC, Australia

\section{Karl Neumann, MD, FAAP, CTM}

Clinical Associate Professor of Pediatrics

Weill Medical College of Cornell University, USA;

Clinical Associate Attending Pediatrician

New York Presbyterian Hospital-Cornell Medical Center

New York, (emeritus) USA;

Attending Pediatrician

Long Island Jewish Hospital, USA;

Director

Family Travel and Immunization Clinic of Forest Hills, Queens, USA

\section{Gilles Poumerol, MD}

Medical Officer

Travel Health, Information \& Communication

Global Capacities Alert \& Response

World Health Organization

Geneva, Switzerland 


\section{Mark A. Read, PhD}

Senior Instructor, Expedition and Wilderness Medicine

Thuringowa Central. Queensland, Australia

\section{Gary Rhodes, PhD}

Director, Center for Global Education

Graduate School of Education and Information Studies

University of California at Los Angeles

Los Angeles, CA, USA

\section{Sara Ritchie, MBChB, MRCGP, DFFP, DTM\&H, MPH, Dip Derm}

Honorary Clinical Fellow in Tropical and HIV Dermatology

University College London Hospitals NHS Foundation Trust London, UK

\section{Edward T. Ryan, MD, FACP, FIDSA, FASTMH}

Co-Director, Global TravEpiNet (GTEN) Program

Director, Travelers' Advice and Immunization Center

Massachusetts General Hospital;

Professor of Medicine, Harvard Medical School;

Professor of Immunology and Infectious Diseases, Harvard School of Public Health

Boston, MA, USA

\section{Patricia Schlagenhauf, PhD}

Professor, University of Zürich Centre for Travel Medicine

Zürich, Switzerland

\section{Eli Schwartz, MD, DTMH}

Professor, Director of the Center for Geographic Medicine

The Chaim Sheba Medical Center

Tel-Hashomer, Israel;

Sackler School of Medicine

Tel-Aviv University

Tel-Aviv, Israel.

\section{Marc T.M. Shaw, DrPH, FRGS, FRNZCGP, FFTM (ACTM), FFTM RCPS (Glasgow),} DipTravMed

Adjunct Professor, College of Public Health, Medical and Veterinary Sciences James Cook University

Townsville, Queensland, Australia;

Medical Director, WORLDWISE Travellers Health Centres

Auckland, New Zealand

\section{David R. Shlim, MD}

Medical Director

Jackson Hole Travel and Tropical Medicine

Wilson Medical Center

Wilson, WY, USA 


\section{Will Smith, MD}

Medical Director, Grand Teton National Park, Teton County Search and Rescue;

Clinical Faculty, University of Washington School of Medicine;

Emergency Medicine, St. John's Medical Center

Jackson, WY, USA

Mark J. Sotir, PhD, MPH

Lead, Surveillance and Epidemiology Team

Travelers' Health Branch

Division of Global Migration and Quarantine

Centers for Disease Control and Prevention

Atlanta, GA, USA

\section{J. Erin Staples, MD, PhD}

Medical Epidemiologist

Arbovirus Disease Branch

Division of Vector Borne Diseases

Centers for Disease Control and Prevention

Fort Collins, CO, USA

\section{Kathryn N. Suh, MD, MSc, FRCPC}

Associate Professor of Medicine

University of Ottawa;

Division of infectious Diseases

University of Ottawa

Ottawa, Canada

Andrea P. Summer, MD, MSCR

Associate Professor of Pediatrics

Medical University of South Carolina

Charleston, SC, USA

Joseph Torresi, MBBS, BMedSci, FRACP, PhD

NHMRC Practitioner Fellow

Department of Microbiology and Immunology

The Peter Doherty Institute for Infection and Immunity

University of Melbourne;

Associate Professor, Department of Infectious Diseases

Austin Hospital

Melbourne, VIC, Australia

\section{Alfons Van Gompel, MD, DTM}

Specialist in Internal Medicine and Tropical Medicine

Associate Professor, Tropical Medicine

Chief Physician of the Medical Services and Travel Clinic of the Institute for Tropical

Medicine

Antwerp, Belgium 
Francisco Vega-López, MD, MSc, PhD, FRCP, FFTM, RCPSG

Consultant Dermatologist and Honorary Professor

University College London Hospitals NHS Foundation TrustLondon, UK

\section{Abinash Virk, MD}

Associate Professor, Internal Medicine

Mayo Medical School

Division of Infectious Diseases

Mayo Clinic

Rochester, MN, USA

\section{Mary J. Warrell, MB BS, FRCP, FRCPath}

Honorary Research Associate

Oxford Vaccine Group

University of Oxford;

Centre for Clinical Vaccinology and Tropical Medicine

Churchill Hospital

Oxford, UK

\section{Annelies Wilder-Smith, MD, PhD}

Professor in Infectious Diseases

Lee Kong Chian School of Medicine

Nanyang Technological University

Singapore

\section{Claire S. Wong, RN, MSc, FFTM RCPS (Glasgow)}

Travel Health Specialist Nurse

WORLDWISE Travellers Health Centres

Auckland, New Zealand

\section{Jane N. Zuckerman, MD, FRCP, FRCPath, FFPH, FFPM, FFTM}

Consultant in Travel Medicine;

Honorary Senior Lecturer, UCL Medical School

University College London, London, UK;

Honorary Consultant, Royal Free London NHS Foundation Trust and Great Ormond Street Hospital for Children NHS Foundation Trust, London, UK;

Adjunct Professor, College of Public Health, Medical and Veterinary Sciences

James Cook University

Townsville, Queensland, Australia 


\section{Preface}

The discipline of travel medicine continues to develop with established roots and structures worldwide. The necessity for the clinical practice of travel medicine in the prevention of ill health has never been more understood than now, with ever-increasing numbers of people traveling and criss-crossing the world alongside the potential hazards that travelers themselves may be exposed to and also the potential inherent risk to public health and populations internationally as a consequence of travel. Protecting travelers and, concomitantly, communities and populations requires the skill and expertise of travel medicine practitioners whose knowledge base is underpinned by continued professional development. Knowledge and education go hand in hand, with specialist training being an essential element, so enabling best clinical practice in a constantly evolving specialty.

The purpose of this book is to support those studying for a qualification or higher degree in travel medicine, and it is hoped that it will be used alongside and complement travel medicine reference books. This book is designed not only to support postgraduate training in the discipline but also to encourage undergraduate training in travel medicine in the curriculum of multidisciplinary healthcare training programs. It has been written in a style to complement lectures, with easily accessible information on the core topics required to enable the day-to-day clinical practice of travel medicine. Authors from different continents were chosen specifically in order to represent a range of views reflecting clinical practice and training courses that are available in different countries through the world.

It is hoped that this book will become a useful aide for those furthering their knowledge in addition to being a practical guide that will enhance the clinical practice and profile of travel medicine as a specialty. For those new to the growing discipline of travel medicine, an aspiration is that this book will stimulate interest and enthusiasm for the discipline for the next generation of travel medicine practitioners.

Jane N. Zuckerman

Gary W. Brunette Peter A. Leggat 


\section{Acknowledgments}

The Editors would like to thank Maria Khan and Oliver Walter of Wiley-Blackwell for their enthusiasm, patience, and commitment that enabled the publication of this new book in travel medicine. In addition, we would like to thank Jennifer Seward and Jasmine Chang, also of Wiley-Blackwell, for all their help in the preparation of this edition. We would also like to thank all the authors for contributing to this book and to supporting the future development of the discipline of travel medicine. In particular, we would like to thank our families for their unfailing support and understanding, specifically Eugene, Tunde, and Pan, without whom this new textbook would not have been realized. 